\title{
Correlation of quality of life and activities of daily living with disease stage in patients with COPD
}

\section{Brahma Prakash, Man Mohan Puri', Lokender Kumar', Anupam Malik ${ }^{2}$, Digambar Behera ${ }^{1}$}

Department of TB and Chest,

Rajan Babu Institute for

Pulmonary Medicine and Tuberculosis, ${ }^{1}$ Department of TB and Chest, LRS Institute of tuberculosis and respiratory diseases, New Delhi, ${ }^{2}$ Department of Respiratory, Critical Care

and Sleep Medicine, Gaba Hospital, Yamunanagar, Haryana, Chandigarh, India

\section{Address for Correspondence:}

Dr. Brahma Prakash,

Department of TB and Chest, Rajan Babu Institute for Pulmonary Medicine and Tuberculosis, Kingsway Camp, GTB Nagar,

New Delhi - 09, India

E-mail: magicbrahma@ rediffmail.com

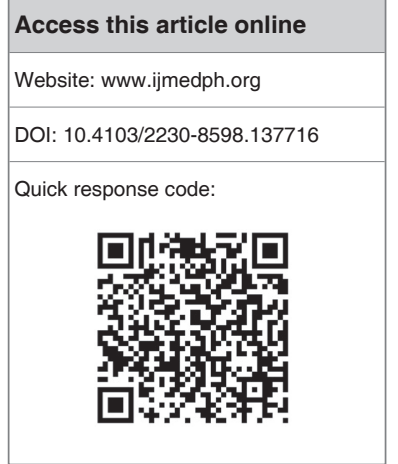

Background: COPD is a chronic disease which may have substantial effect on quality of life of patients. Aim: The aim of this study is to study the impact of COPD on activities of daily living and quality of life of patients and to correlate the impact with severity of disease in the set up of Indian conditions. Materials and methods: In this prospective study conducted at a tertiary level hospital, stable COPD patients without any other coexisting co-morbidity were enrolled. The severity of COPD was classified as per GOLD 2006 guidelines. The quality of life and impact of COPD on activities of daily living was assessed using Seattle obstructive lung disease questionnaire translated in local language, 6 minutes walk test and visual analog scale for dyspnoea. Results: Seventy eight patients and 20 controls were enrolled for the study. The scores for physical functions, emotional functions, coping skills and treatment satisfaction obtained from questionnaire were decreased in COPD patients. The physical function and emotional function score, decreased significantly $(P<0.05)$ when compared from mild through moderate, severe and very severe stages of COPD, these scores also correlated positively with percent predicted FEV values in spirometry ( $r=0.855$ and $r=0.735$ respectively) There was a significant fall in the six minute walk distance as the stage of disease progressed. The Visual analog scale score significantly increased $(P<0.05)$ with the stage of COPD. Conclusion: Assessing quality of life and ability to perform activities of daily living is also important for assessing the disease severity.

Key words: COPD, Global Initiative for Chronic Obstructive Lung Disease (GOLD), Health-related quality of life (HRQoL), Seattle obstructive lung disease Questionnaire (SOLDQ)

\section{INTRODUCTION}

Health related quality of life (HRQOL) measures the impact of an individual's health on his or her ability to perform and enjoy the activities of daily life. ${ }^{[1]}$ Chronic Obstructive Pulmonary Disease (COPD) has substantial impact on quality of life, impairing not only physical, but also psychological and social functions. Therefore, in addition to assessment of degree of airflow obstruction by spirometry, it is important to measure health related quality of life in these patients. Various tools and questionnaires have been developed to assess the HRQoL. One of such tools for chronic respiratory diseases is: Seattle obstructive lung disease Questionnaire (SOLDQ) ${ }^{[2]}$ It is reliable, valid and measures physical and emotional function, coping skills and treatment satisfaction in patients with COPD. It is self administered, brief and can be scanned via computer. The aim of this study was to study the impact of COPD on activities of daily living and quality of life in these patients and to correlate the impact with severity of disease in the set up of Indian conditions using Seattle obstructive lung disease Questionnaire. The study has been approved by the Research committee and Ethical committee of the Institute. This questionnaire evaluates longitudinal differences within persons over time and also discriminative purpose, such as differentiating between groups of patients with varying disease severity. The physical function scale assesses the degree of dyspnea and the extent of physical limitation. The emotional function scale measures the impact of the disease on patient's psychological well-being. The coping skills scale measures self-efficacy which reflects a patient's conviction regarding his/her ability to achieve a certain outcome and is an important determinant of successful behavior change. 
The fourth dimension, treatment satisfaction, measures how satisfied patients are with the therapy they are getting for COPD. The higher the score on each dimension of the questionnaire, the better is the health related quality of life in patients.

\section{MATERIALS AND METHODS}

A prospective study was designed to verify whether the impact of activities of daily living and quality of life in patients suffering from Chronic obstructive pulmonary disease correlates with the severity of disease. The study was approved by research and ethical committee of Institute. Seventy eight stable COPD patients with no history of exacerbation in past 4 weeks attending the chest clinic of institute were enrolled. Patients with co-morbidities were excluded so that effect of COPD on quality of life could be studied without contribution of other co-morbid conditions like past history of tuberculosis, hypertension, diabetes, liver disease, renal disease and other neurological and muscular disabilities. Twenty healthy individuals were enrolled as controls. Informed written consent was obtained from all the participants. A detail clinical history and physical examination, routine blood tests, chest $\mathrm{X}$-ray, and spirometry were performed for each participant. All the participants filled the Seattle obstructive lung disease questionnaire translated in local language and performed six-minute walk distance test as per American Thoracic Society guidelines. ${ }^{[3]}$ Seattle obstructive lung disease questionnaire translated in Hindi language was earlier validated in our department to study the impact of pulmonary rehabilitation on morbidity due to chronic obstructive lung disease in 30 patients. The Hindi version of the SOLDQ was developed following the forward-backward translation procedure with independent translations and counter-translations. The dyspnea level of participants was also assessed by Visual analog scale. ${ }^{[4]}$ The staging of severity of COPD was done according to GOLD 2006 guidelines $^{[5]}$ as mild, moderate or severe or very severe disease based on the spirometric evaluation.

\section{RESULTS}

Seventy eight stable COPD patients with mean age of $52.5 \pm$ 10.18 years were enrolled. There were $19(24.4 \%)$ female patients with mean age of 48.4 years. The mean age of male patients was 53.8 years. The mean age of controls was $51.30 \pm 9.87)$ years. The disease severity was classified as per GOLD 2006 guidelines. Twenty two patients had mild and 21 had moderate disease. There were 23 patients with severe and 12 with very severe COPD. The patient characteristics of each study group are shown in Table 1.

Bidi smoking was found to be the most prevalent form of smoking in our patient group. The smoking preferences and smoke exposures of patients have been shown in Table 2 .

The physical function score, emotional function score, coping skills scores, treatment satisfaction scores, six minutes walk distance and Visual analog scale scores is shown in Table 3. Analysis of the data was done with Microsoft Excel XP (Microsoft, Seattle WA) and SPSS version 13.0 software (SPSS inc., Chicago, IL). The collected data has been expressed as mean \pm SD or median with inter-quartile range (1st quartile-third quartile) depending on the distribution of data. Each parameter was tested for normality in the distribution of data using standard normality tests (D' Agostino-Pearson omnibus normality test and Shapiro-Wilk test), and subsequently appropriate parametric or non-parametric tests were applied. The variables in the various groups of patients were compared using one way analysis of variance (ANOVA) test and post hoc analysis between the groups. The relationship between two parameters was evaluated using Pearson's correlation coefficient or Spearman's rank correlation coefficient as appropriate. A value of $P<0.05$ was considered statistically significant. The physical function score and emotional function score, decreased significantly $(P<0.05)$ when compared from mild through moderate, severe and very severe stages of COPD [Table 3]. The physical function score for mild through moderate, severe and very severe stages of COPD was $85.57 \pm$ $5.48,72.85 \pm 10.52,56.91 \pm 9.84$, and $44.18 \pm 13.49$ respectively. The emotional function score for mild through moderate, severe and very severe stages of COPD was $96.65 \pm 5.48,84.6 \pm 13.1$, $76.08 \pm 12.37$, and $57.22 \pm 19.63$ respectively. Coping skills scores were also decreased significantly $(P<0.05)$ when compared from mild through moderate, severe and very severe stages of COPD. The treatment satisfaction scores did not differ significantly with change in severity of the disease $(P$ value $>0.05)$. The treatment satisfaction score could not be compared with control group because the controls were healthy subjects and not on any treatment. The health related quality of life dimensions scores in relation to COPD severity according to GOLD guidelines are shown in [Figure 1]. The Forced expiratory volume in first second $\left(\mathrm{FEV}_{1}\right)$ actual as well as percent predicted $\mathrm{FEV}_{1}$ correlated positively with the physical function score $(r=0.827, P=0.000$ and $r=0.855, P=0.000$ respectively) and emotional function score $(r=0.725, P=0.000$ and $r=0.735, P=0.000$ respectively) as shown in [Figures 2 and 3].

\begin{tabular}{|c|c|c|c|c|c|c|}
\hline Dimensions & Controls & Mild COPD & Moderate COPD & Severe COPD & Very severe COPD & $P$ value \\
\hline Age (in years) & $51.3(9.8)$ & $51.09(10.7)$ & $53.7(11)$ & $52.4(9.7)$ & $53.2(9.2)$ & 0.913 \\
\hline Sex & $M-15 F-5$ & M-16 F-6 & $M-16$ F-5 & $M-17$ F-5 & $M-10 \mathrm{~F}-2$ & - \\
\hline Hemoglobin (gm\%) & $12.6(0.7)$ & $14.5(1.4)$ & $14.5(1.3)$ & $14.4(1.5)$ & $15.1(2.08)$ & 0.000 \\
\hline Height (in cms) & $161(6.9)$ & $157.2(8.7)$ & $159.2(10.3)$ & $158.5(5.7)$ & $158.9(7.3)$ & 0.65 \\
\hline Weight (in kgs) & $59.9(14.7)$ & $50.8(9.6)$ & $51.3(12.7)$ & $48.4(11.3)$ & $46.9(12.9)$ & 0.016 \\
\hline Body mass index (wt/ht in mts ${ }^{[2]}$ ) & $22.96(4.44)$ & $20.53(3.68)$ & $20.11(3.99)$ & $19.12(3.68)$ & $18.38(4.13)$ & 0.011 \\
\hline
\end{tabular}

Values are expressed as Mean (Standard deviation), except in row with heading 'sex' which represent absolute numbers 
The six minutes walk distance decreases with the severity of disease. It was $492 \pm 63.6,464.6 \pm 76.7,394.2 \pm 69$, and $331.1 \pm 80.6$ meters for mild, moderate, severe, and very severe COPD patients respectively. In control group 6MWD was $530 \pm 53$ meters. The fall in 6MWD was statistically significant as the disease progress in severity from moderate to severe and very severe as per the GOLD 2006 guidelines. There was no statistically significant difference in 6MWD as the disease increases in severity from mild and moderate COPD $(P$ value $=0.192)$. The physical function score of SOLDQ which measures the physical activity level of COPD patients correlated positively with 6MWD $(r=0.709, P=0.000)$, after controlling for confounding variables including height, weight, Body mass index, hemoglobin level and age [Figure 4] The Visual analog scale score for dysponea significantly increases $(P<0.05)$ as the disease progress from mild through moderate, severe, and very severe COPD [Table 3]. VAS for mild, moderate, severe, and very severe COPD patients was $15.68 \pm 7.28,52.86 \pm 15.21,71.09 \pm$ 12.96 and $88.33 \pm 8.87$ respectively [Table 1]. The VAS correlated negatively with physical functions scores $(r=-0.827, P=0.000)$ and emotional function score of SOLDQ significantly $(r=-0.744$, $P=0.00)$.

\section{DISCUSSION}

COPD is a disease of adults occurring usually after 40 years of age. Its occurrence depends upon many factors and Tobacco smoking is the most important risk factor. In our study, mean age of 78 enrolled COPD patients was 52.5 years and about two third of patients $(n=59)$ were in the productive age group and less than 60 years of age. The eldest patient in our study was 70 years old and six patients were below 40 years of age. Women are more susceptible to the disease and develop COPD at an earlier age than the men, despite of lesser duration of exposure to smoke. ${ }^{[6]}$ However, in our study there were only $25 \%(n=19)$ female patients.. Other studies

\begin{tabular}{|c|c|}
\hline $\begin{array}{l}\text { Smoking preference } \\
\text { and exposure }\end{array}$ & $\begin{array}{c}\text { Number of } \\
\text { patients(percentage) }\end{array}$ \\
\hline Only Bidi's & $41(52.6)$ \\
\hline Only Cigarette's & $8(10.2)$ \\
\hline Only Hukka & $1(1.3)$ \\
\hline Only biomass(Chulha) smoke & $9(11.4)$ \\
\hline More than 1 form of smoke & $19(24.4)$ \\
\hline
\end{tabular}

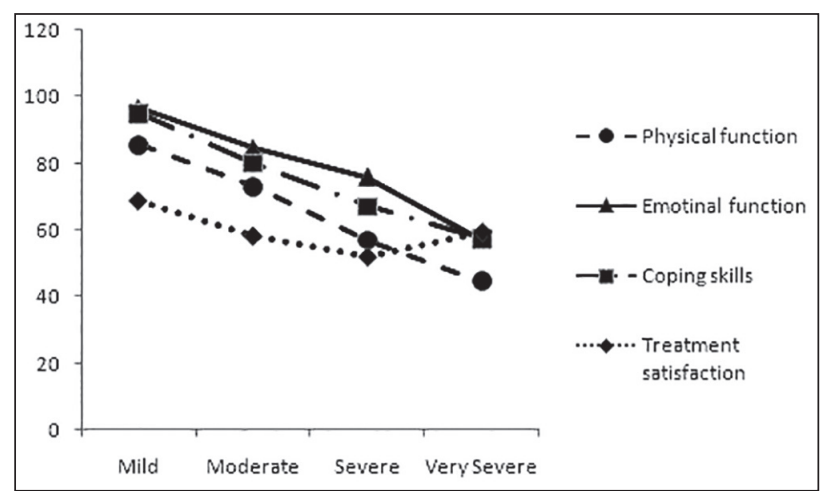

Figure 1: $\mathrm{HRQOL}$ dimensions scores in relation to COPD severity according to GOLD guidelines

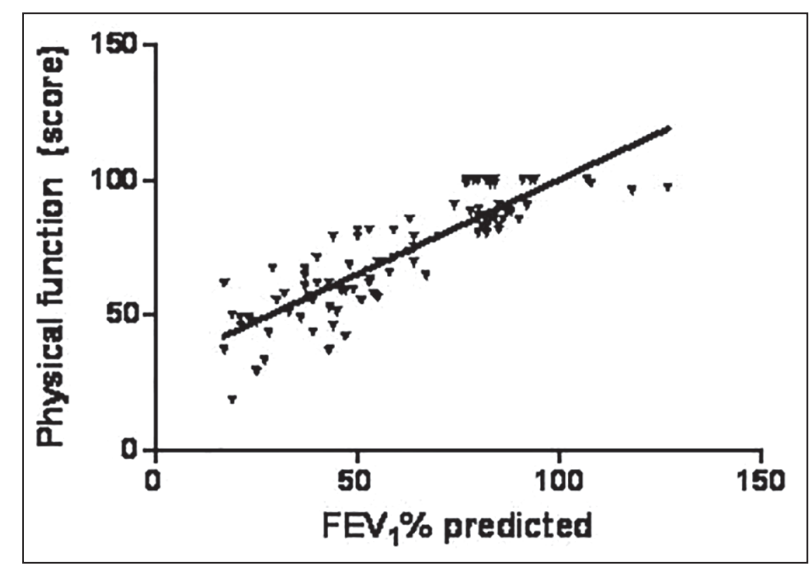

Figure 2: Correlation between $\mathrm{FEV}_{1}$ percent predicted ( $\mathrm{x}$-axis) and Physical function scores (y-axis) Pearson $r=0.855, P=0.000$

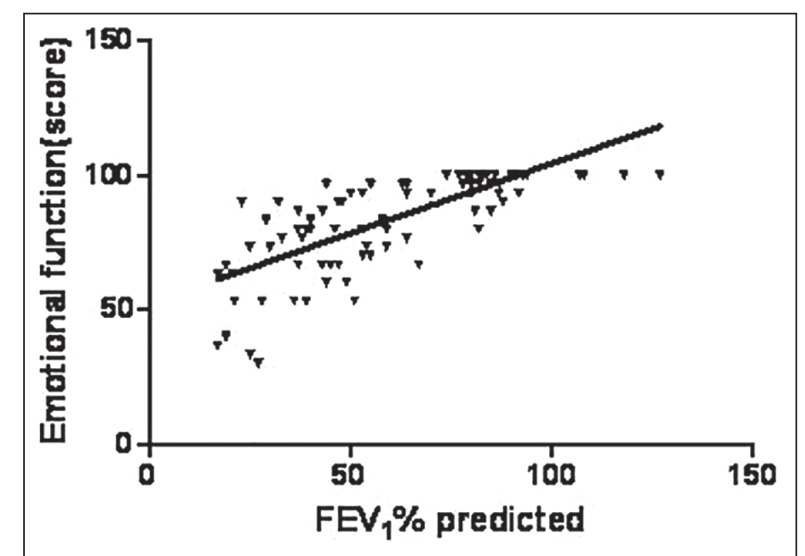

Figure 3: Correlation between $\mathrm{FEV}_{1}$ percent predicted (x-axis) and Emotional function scores (y-axis) Pearson $r=0.735, P=0.000$

\begin{tabular}{|c|c|c|c|c|c|c|}
\hline Dimensions & Controls & Mild COPD & Moderate COPD & Severe COPD & Very severe COPD & $P$ value \\
\hline Physical function & $99.4(1.08)$ & $85.57(3.02)$ & $72.85(10.52)$ & $56.91(9.8)$ & $44.18(13.49)$ & 0.000 \\
\hline Emotional function & $100(0)$ & $95.6(5.4)$ & $84.6(13.1)$ & $76.08(12.37)$ & $57.22(19.63)$ & 0.000 \\
\hline Coping skills & $100(0)$ & $95.08(5.53)$ & $80.1(15.79)$ & $67.17(15.53)$ & $57.31(17.27)$ & 0.000 \\
\hline Treatment satisfaction & $\mathrm{NA}^{*}$ & $68.72(17.62)$ & $58.33(23.82)$ & $52.15(17.56)$ & $58.33(25.18)$ & 0.06 \\
\hline Six minutes walk distance (meters) & 530. (53) & $492.9(63.6)$ & $464.6(76.7)$ & $394.2(69)$ & $331.1(80.6)$ & 0.000 \\
\hline Visual analog scale & 0 & $15.68(7.28)$ & $52.86(15.21)$ & $71.09(12.96)$ & $88.33(8.87)$ & 0.000 \\
\hline
\end{tabular}




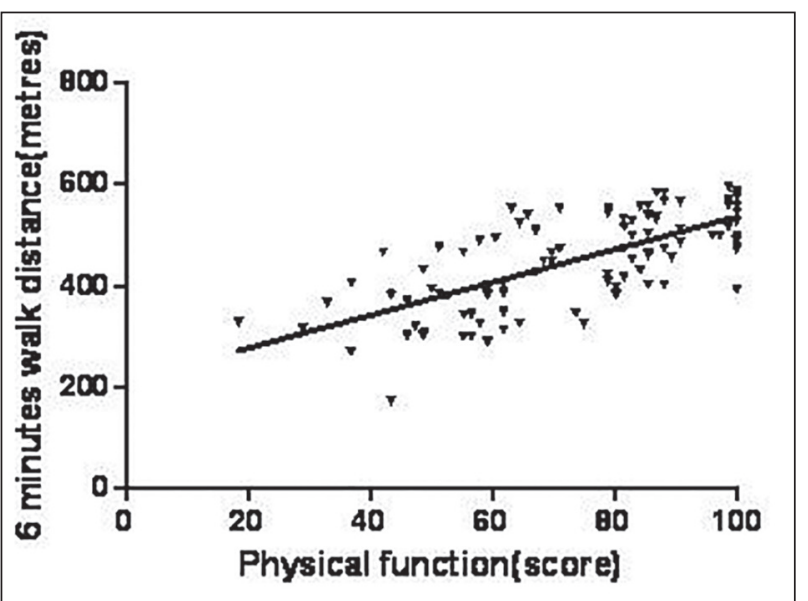

Figure 4: Correlation between physical function score ( $\mathrm{x}$-axis) and six minutes walk distance (y-axis) Pearson $r=0.709, P=0.000$

have also observed this age related gender difference. ${ }^{[7,8]}$ Often the women and their family members neglect the symptoms of disease occurring in women ${ }^{[9]}$ and less number of women are able to utilize health care facilities due to various social factors. ${ }^{[10]}$

Morbidities due to COPD affect all aspects of life, including work and home life, physical and sexual aspects of marriage, internal emotional factors and dependence needs. ${ }^{[11]}$ GOLD guidelines are widely used to categorize COPD patients into various stages on the basis of percent predicted $\mathrm{FEV}_{1}$ and $\mathrm{FEV}_{1} / \mathrm{FVC}$ ratio. In this study disease severity was determined as per GOLD 2006 guidelines. ${ }^{[5]}$ The associated loss of physical capacity and the adverse psychological effects of the disorder contribute greatly to the activities of daily living (ADL) and health related quality of life of the patients. Activities of daily living are the activities which are performed at suboptimal level of maximum exercise capacity of the individual. Association between health related quality of life (HRQoL) and disease severity based on $\mathrm{FEV}_{1}$ had been seen ${ }^{[12,13]}$ with various disease specific questionnaires like chronic respiratory disease questionnaire (CRQ), St. George respiratory questionnaire (SGRQ). Seattle obstructive lung disease questionnaire (SOLDQ) has been specifically designed and studied to know the effect of COPD on quality of life. The physical function dimension score of the SOLDQ measures the impact on quality of life due to the limitations of physical activities, performed in day to day activities. The more the score of this dimension of questionnaire, the better is the ability of individual with COPD to perform activities of daily living. As the disease progressed in severity, the physical function scores decreased significantly. In our study patients with COPD in all stages of disease have significantly reduced physical functioning scores. The mean physical functioning score of SOLDQ ranged from 85.5 in stage I (mild COPD) to 44 in GOLD stage IV (very severe COPD) disease. Similarly, Elisabeth $\mathrm{S}$ et al, had also observed statistically significant difference in SGRQ score in all stages of COPD. ${ }^{[14]}$ Antonelli Inclazi R et al, ${ }^{[15]}$ observed significant differences in SGRQ scores between stages III and IV of disease, whereas changes from stage 0 to stage II were not significant. They had classified their patient as per GOLD 2001 guidelines. The emotional function or psychological effects of the disease and the coping skills are other determinants of quality of life. ${ }^{[16-18]}$ In our patients emotional function score, decreased significantly $(P<0.05)$ when compared from mild through moderate, severe and very severe stages of COPD. The deterioration in coping skills score was not found statistically different in patients with severe to very severe stage of disease $(P=0.095)$ as these skills in these patients were probably jeopardized due to more severe symptoms and more limitation in activities of daily living. The treatment satisfaction scores did not differ significantly with change in severity of the disease. This implies that patients were not fully satisfied by the treatment, they were receiving. The reason for which might be that many of them were from poor socioeconomic backgrounds and could not afford all the medicines and treatment options available, which could have improved their symptoms further. Also, the patients with severe disease have more symptoms, so treatment they receive might not eliminate all of their symptoms completely, in spite of optimal treatment, resulting in poor quality of life scores and reduced scores of treatment satisfaction dimension. 6-MWD can be an indicator of ability of physical activity of the patient. As the disease severity progresses the 6 minute walk distance in COPD patients gradually decreases with decrease in $\mathrm{FEV}_{1}{ }^{\left[{ }^{[19]}\right.}$ In our study there was statistically significant decrease in 6-MWD from moderate to severe and very severe COPD patients classified as per the GOLD guidelines. The positive correlation between the physical function score and 6-MWD suggests that the physical activities are reduced with increasing severity of COPD. Another uni-dimensional scale like Visual analog scale may be combined with a multidimensional scale (like SOLDQ) for measuring disease specific quality of life. VAS measure subjective feeling of breathlessness in COPD patients. ${ }^{\left[{ }^{[0]}\right.}$ In our study, we found that VAS scores means were lower in patients with COPD as compared to healthy controls in all stages of COPD. The recent GOLD guidelines has also emphasized on the use of quality of life scores and grading of breathlessness in the form of MMRC grade for classification of disease staging and the management is based on this classification. ${ }^{[21]}$

The study has limitations because of small number of patients in all four groups and it is suggested to confirm these results in a study with large number of patients in each group. Secondly, patients with exacerbations of COPD were excluded. Patient with each exacerbation has more deterioration in quality of life and these patients were excluded in our study and therefore, the effect of exacerbations on the activities of daily living has not been studied in this study. COPD has impact on activities of daily living and health related quality of life. Spirometry is used to confirm the diagnosis of COPD, but the spirometry parameters alone may not be able to classify diseases severity, and the quality of life scores are also required to assess the disease severity. Therefore, these scores may be helpful in providing physicians with the ability to monitor the quality of life and activities of daily living, thereby suggesting change in the health status of the patient which may be caused by change in COPD severity. Suffering from Chronic obstructive pulmonary disease correlates with the severity of disease. 


\section{ACKNOWLEDGEMENTS}

Our Special thanks to Dr. Shin-Ping Tu for his permission to use Seattle obstructive lung disease Questionnaire (SOLDQ) to develop the Hindi version of the SOLDQ.

\section{REFERENCES}

1. Curtis JR, Deyo RA, Hudson LD. Pulmonary rehabilitation in chronic respiratory insufficiency. 7. Health-related quality of life among patients with chronic obstructive pulmonary disease. Thorax 1994;49:162-70.

2. Tu SP, McDonell MB, Spertus JA, Steele BG, Fihn SD. A new selfadministered questionnaire to monitor health-related quality of life in patients with COPD. Ambulatory Care Quality Improvement Project (ACQUIP) Investigators. Chest 1997;112:614-22.

3. ATS statement: Guidelines for the six-minute walk test. Am J Respir Crit Care Med 2002;166:111-7.

4. Huskisson EC. Measurement of pain. Lancet 1974;2:1127-31.

5. GOLD. Global Initiative for Chronic Obstructive Lung Disease Workshop Report: Global Strategy for the Diagnosis, Management and Prevention of COPD. Available from: http://www.goldcopd.com. [Last accessed on 2006 Aug 8].

6. De Torres JP, Casanova C, Hernández C, Abreu J, Aguirre-Jaime A, Celli BR. Gender and COPD in patients attending a pulmonary clinic. Chest 2005;128:2012-6.

7. Xu X, Li B, Wang L. Gender difference in smoking effects on adult pulmonary function. Eur Respir J 1994;7:477-83.

8. Leidy NK, Traver GA. Psychophysiologic factors contributing to functional performance in people with COPD: Are there gender differences? Res Nurs Health 1995;18:535-46.

9. Franks P, Clancy CM, Naumburg EH. Sex, access, and excess. Ann Intern Med 1995;123:548-50.

10. Nandraj S, Madhiwalla N, Sinha R, Jesani A. Health, Households and Women's Lives: A study of illness and childbearing among women in Nasik District, Maharashtra, CEHAT 1999.

11. Anderson $\mathrm{KL}$. The effect of chronic obstructive pulmonary disease on quality of life. Res Nurs Health 1995;18:547-56.

12. Katsura H, Yamada K, Wakabayashi R, Kida K. The impact of dyspnoea and leg fatigue during exercise on health-related quality of life in patients with COPD. Respirology 2005;10:485-90.

13. De La Fuente Cid R, De La Iglesia Martínez F, Ramos Polledo V, Pellicer Vázquez C, Nicolás Miguel R, Diz-Lois Martínez F. Factor analysis of the health related quality of life of patients with stable chronic obstructive pulmonary disease. Arch Bronconeumol 2001;37:411-6.

14. Stahl E, Lindberg A, Jansson SA, Rönmark E, Svensson K, Andersson F, et al. Health-related quality of life is related to COPD disease severity. Health Qual Life Outcomes 2005;3:56.

15. Antonelli-Incalzi R, Imperiale C, Bellia V, Catalano F, Scichilone N, Pistelli $\mathrm{R}$, et al. Do GOLD stages of COPD severity really correspond to differences in health status? Eur Respir J 2003;22:444-9.

16. Martínez Francés ME, Perpiñá Tordera M, Belloch Fuster A, Martínez Moragón EM, Compte Torrero L. Impact of baseline and induced dyspnea on the quality of life of patients with COPD. Arch Bronconeumol 2008;44:127-34.

17. Guyatt GH, Berman LB, Townsend M, Pugsley SO, Chambers LW. A measure of quality of life for clinical trials in chronic lung disease. Thorax 1987;42:773-8.

18. Cully JA, Graham DP, Stanley MA, Ferguson CJ, Sharafkhaneh A, Souchek $J$, et al. Quality of life in patients with chronic obstructive pulmonary disease and comorbid anxiety or depression. Psychosomatics 2006;47:312-9.

19. Mak VH, Bugler JR, Roberts CM, Spiro SG. Effect of arterial oxygen desaturation on six minute walk distance, perceived effort, and perceived breathlessness in patients with airflow limitation. Thorax 1993;48:33-8.

20. Nishiyama O, Taniguchi H, Kondoh Y, Nishimura K, Suzuki R, Takagi K, et al. The effectiveness of the visual analogue scale 8 in measuring healthrelated quality of life for COPD patients. Respir Med 2000;94:1192-9.

21. Global Strategy for Diagnosis, Management, and Prevention of COPD Updated February 2013. Evidence-based guidelines for COPD diagnosis, management, and prevention, with citations from the scientific literature. Available from: http://www.goldcopd.com. [Last accessed on 2013 Feb 8]

How to cite this article: Prakash B, Puri MM, Kumar L, Malik A, Behera D. Correlation of quality of life and activities of daily living with disease stage in patients with COPD. Int J Med Public Health $2014 ; 4: 275-9$

Source of Support: Nil, Conflict of Interest: No author has any conflicts of interest. 